\title{
Transdisciplinaridade como base para gestão de processos em Serviços de Saúde
}

\begin{abstract}
Marcos Paulo Valadares de Oliveira
Professor adjunto do departamento de administração da Universidade Federal do Espírito Santo. Possui graduação em Administração pela Universidade Federal de Minas Gerais (2003), mestrado (2006) e doutorado (2009) em Administração - Gestão de Cadeias de Suprimentos e Operações pela Universidade Federal de Minas Gerais.
\end{abstract}

mpvo@ufmg.br

\section{Marcelo Santos Silva}

Médico infectologista, com experiência em coordenação de Serviço de Controle de Infecções.

marcelos40@gmail.com

RESUMO: Este ensaio teórico apresenta uma discussão acerca da gestão de processos em serviços de saúde, considerando o aumento crescente da complexidade dos procedimentos, bem como as dificuldades de controle e pulverização de informações trazidas pelos movimentos de terceirização. A argumentação é desenvolvida sustentada em exemplos e caracterizações de situações cotidianas que demonstram a necessidade de se adotar uma visão transdisciplinar na gestão de processos em serviços de saúde que possa alinhar as diversas percepções dos diversos atores que compõe a cadeia de valor, sejam eles internos ou externos à organização, com o objetivo de garantir que os interesses e necessidades dos clientes finais possam prevalecer frente a interesses de maximização de desempenho nos silos funcionais.

PALAVRAS-CHAVE: Gestão de Processos. Transdisciplinaridade. Valor

\section{Transdisciplinarity grounding process management in Health Services.}

ABSTRACT: This theoretical essay presents a discussion of case process management in health services, considering the complexity increase of procedures, as well as the difficulties of control and spreading of information brought by the movement of outsourcing. The argument is developed in sustained characterizations and examples of everyday situations that demonstrate the need to adopt a transdisciplinary view of process management in health services that can align the diverse perceptions of different actors that make up the value chain, whether internal or external to the organization with the goal of ensuring that the interests and needs of final customers can prevail against the interests of maximizing performance in functional areas.

KEYWORDS: Process management. Transdisciplinarity. Value 


\section{INTRODUÇÃO}

Conforme dados apresentados no relatório de estatísticas da saúde do IBGE (2006) (IBGE, 2006), muitos esforços têm sido empreendidos, por diversos atores da sociedade em geral, com o intuito de desenvolver uma maior capacidade na criação de valor nas atividades de prestação de serviços de saúde para a população brasileira. Ainda com base nesses dados, ao avaliarmos a dinâmica nas redes de valor no setor de saúde, a tendência de aumento nos últimos anos da terceirização de serviços apresentase em destaque, 34,6\% de aumento em 2005 em relação a 2002 (IBGE, 2006). Tal movimento aponta, portanto, para um aumento na complexidade das relações e processos nas cadeias de valor hospitalares, fundamentalmente, pela incorporação de novos atores advindos da terceirização de funções.

Conforme argumentam (Normann \& Ramírez, 1993), nosso pensamento atual acerca de valor está baseado nas premissas e no modelo de uma economia industrial em que toda empresa ocupa uma posição de relevância em uma cadeia. A montante os fornecedores proporcionam entradas que a empresa utiliza como insumos para gerar valor e entregar, à jusante aos clientes, próximos atores da cadeia.

Atualmente, a competição global, a dinâmica dos mercados e novas tecnologias estão abrindo novas oportunidades para a criação de valor. Neste sentido, a análise estratégica não deve se pautar somente em uma empresa ou mesmo um setor, mas no sistema de criação de valor, no qual diferentes atores econômicos - fornecedores, parceiros de negócio, clientes e demais stakeholders - trabalham em conjunto.

Assim, a estratégia deve ser considerada como a forma que uma empresa define seu negócio e conecta os únicos dois recursos que realmente interessam na economia atual: conhecimento e relacionamentos; ou seja, as competências de uma empresa com seus clientes e fornecedores (Normann \& Ramírez, 1993).

Considerando a quase impossibilidade de controlar precisamente todos os processos em um hospital a partir de uma visão puramente funcional, torna se imperativo uma atenção voltada para os processos estratégicos sob uma perspectiva transdisciplinar, compreendendo o papel dos diversos atores na organização, sejam eles atores diretos ou terceirizados. Diante das limitações de uma visão ampla dos processos trazida pela gestão funcional, a gestão é direcionada a executar e controlar os processos sob uma referência técnica e legal buscando garantir minimamente o alinhamento à estratégia do seu negócio.

Complementarmente, ao definirem as bases para o gerenciamento efetivo de cadeias de suprimentos, (Lee \& Billington, 1992) argumentam acerca de três pontos-chave considerados como fundamentais, são eles: i) conectividade entre os membros (relacionamentos); ii) alinhamento dos sistemas de suporte interorganizacionais (conhecimento); e iii) compartilhamento de recursos - informações e expertises (relacionamentos + conhecimento).

Ao considerar o contexto da administração hospitalar, a discussão acerca das regras e processos, bem como a identificação de atores e papéis necessários à co-produção de valor, alcança relevância e tempestividade. Tal contexto se configura sob o fato de que os processos nas instituições de saúde, ao se tornarem complexos e com maior impacto potencial, foram também acrescidos de riscos e com custos cada vez mais significativos. Um exemplo disto são os tratamentos bastante resolutivos para doenças como o câncer que antes eram abordados com tratamentos paliativos de baixa complexidade técnica e atualmente são abordados com tratamentos muitas vezes curativos, de alta complexidade, mas com elevados riscos de iatrogenias e danos.

Este ensaio procura apresentar algumas reflexões a gestão funcional versus a gestão por processos sob uma perspectiva transdisciplinar na cadeia de suprimentos hospitalar para criação de valor nos serviços de saúde no Brasil, considerando a tendência de aumento na complexidade dos processos gerada por um aumento no movimento de terceirização de serviços, bem como pelo aumento na complexidade dos processos.

\section{GESTÃO DE CADEIAS DE SUPRIMENTOS EM HOSPITAIS}

As cadeias de suprimentos hospitalares, como aquelas representantes de outros setores da economia, são compostas de diferentes categorias de fornecedores e clientes, com diferentes características de suprimento e demanda. Diversas irregularidades identificadas no abastecimento e na "falta de material" são frequentemente identificadas em serviços de saúde e geram impactos negativos sobre o desempenho e a imagem junto aos profissionais de saúde e à população (Infante \& Santos, 2007).

Um exemplo de tal ineficiência foi apontado por (SCHNEIDER, 2006) ao estudar o processo de fornecimento de hortifrutigranjeiros para hospitais, uma vez que as normas técnicas não são seguidas por parte dos fornecedores e, por parte dos hospitais, o recebimento não é adequado e em geral, o 
profissional que recebe as mercadorias não tem conhecimento técnico, nem tampouco segue a legislação vigente para este procedimento.

A tendência no setor parece ser a de considerar que todos os problemas de abastecimento dos serviços de saúde se devem à insuficiência de recursos orçamentários. Sem deixar de considerar os impactos negativos das disfunções na execução orçamentária no abastecimento, os desperdícios e a má utilização de insumos e equipamentos, a escassa qualificação dos profissionais da área de abastecimento e a pouca atenção ao planejamento logístico nas organizações públicas e privadas de saúde são pontos que não podem ser negligenciados pela gestão (Infante \& Santos, 2007).

As cadeias de suprimentos hospitalares são compostas por atividades complexas que incorporam seqüências de ações definidas para a geração de seus produtos (os chamados "procedimentos"). Cada procedimento demanda um mix específico de insumos (bens) e processos de trabalho (serviços), cuja composição pode variar entre diferentes organizações de saúde, diferentes tipos de pacientes e profissionais.

Os gestores de cadeias de suprimentos devem se comprometer com uma visão crítica e garantir que os processos estejam voltados para a entrega de valor ao paciente, considerando que ele não está à busca do consumo de produtos (procedimentos) e sim pelo desfecho ou resultado advindo desse consumo (Grossman, 1972). O desfecho esperado do consumo de um produto ou conjunto de produtos seria a melhora do estado de saúde do paciente no melhor tempo e sem intercorrências ou danos.

\section{GESTÃO DE PROCESSOS}

De acordo com Peter Drucker, a gestão deve ser considerada a inovação mais importante do século 20. Técnicas para a condução de grandes corporações, utilizadas pioneiramente por homens como Alfred Sloan da General Motors e refinada pela maioria das escolas de negócio de elite, auxiliaram na condução de um século de prosperidade global sem precedentes.

Nos últimos tempos, entretanto, a maior parte dos ícones conquistaram sua reputação ao atacar culturas corporativas arraigadas, quebrando hierarquias coorporativas, minando as estruturas corporativas e, em alguns casos, utilizando táticas de revolução em uma tentativa desesperada de "fazer com que os elefantes dancem". Os melhores gerentes corporativos se tornaram, portanto, os inimigos da tradicional corporação.

De acordo com (Murray, 2010), as razões são muito claras: corporações são burocracias e gerentes são burocratas e, portanto, sua tendência fundamental é pela auto-perpetuação e quase por definição, são resistentes a mudanças.

As corporações atuais são desafiadas a criar estruturas que motivam e inspiram os trabalhadores e, efetivamente, consigam enfrentar a competitividade incansável de um mercado global. No ramo hospitalar não é diferente, o turismo de saúde, por exemplo, vem rompendo barreiras geográficas e gerando turbulência no segmento. No Brasil, tal movimento já pode ser observado, mesmo que em estágio embrionário, nos hospitais Albert Einstein, Sírio-Libanês, Oswaldo Cruz, Samaritano e Hospital do Coração que anunciaram a formação de um grupo (Estadão, 2010) para garantir uma fatia do mercado mundial de turismo médico, que movimenta por ano cerca de US\$ 60 bilhões. Estima-se que em 200548 mil estrangeiros buscaram tratamento médico no Brasil - a maioria deles cirurgia plástica. Entre 2007 e 2009, segundo a Deloitte Center for Health Solutions, foram cerca de 180 mil. Na Tailândia, apenas em 2007, esse número chegou a 1,2 milhão.

Diante de tantos desafios, advindos de diversas direções, a gestão orientada por processos assume um papel cada vez mais importante. O dia a dia de uma empresa é composto por uma variedade de processos. Conforme argumentam (Yaxiong, Zhen, Guoquan, \& Boqing, 2008), a empresa do conhecimento é caracterizada não somente por grandes quantidades de dados altamente redundantes envolvidos em informações em vários processos, mas também pela capacidade de extrair dos processos regras e experiências relacionadas, denominadas de conhecimento do processo.

A complexidade transdisciplinar nas instituições de saúde difere da indústria pelo grande número de variáveis nos processos que interferem na qualidade e no prazo de entrega dos produtos primários e secundários. As instituições frequentemente tentam controlar processos, mas falham por não alinharem a uma estratégia do negócio definida pela alta gestão, acordada e desdobrada em todos os níveis. Em uma visão por processos, em contraposição à visão funcional, a valorização não deve tomar como 
referência a eficiência dos atores isoladamente, mas pela sua relevância em relação ao produto final. Apenas uma estratégia de negócio bem definida e desdobrada em todos os níveis administrativos e assistenciais possibilita uma hierarquização dos processos a serem privilegiados, possibilitando inovações que agreguem valor ao produto final. O reconhecimento e classificação dos processos e produtos, alinhados a uma estratégia possibilitam uma gestão que avalie os resultados para retroalimentação das estratégias. Uma visão transdisciplinar e estratégica possibilitará uma gestão dos processos que não pertencem a nenhuma das disciplinas (setores, profissionais, especialistas, etc.) em separado, mas são alimentados por todas elas (Morin, 2005).

O dia-a-dia de um hospital é cheio de interrupções, problemas de comunicação, movimentos equivocados e procedimentos adicionais para resolver problemas causados por processos inadequados. Empregados e administradores frequentemente pensam que seu trabalho, ou o valor que eles trazem para uma organização, está na sua habilidade de lidar com problemas. Quando há falta de suprimentos, corremos e conseguimos. Quando nossos ambientes estão mal projetados e a carga de trabalho está grande, aumentamos nossa velocidade. Quando os prontuários não chegam ao consultório médico, fazemos inúmeras ligações telefônicas até localizá-los. Estes são procedimentos contingenciais que não previnem a reincidência dos problemas, pois não atacam as causas. É preciso, portanto, compreender os hospitais como um conjunto de processos transdisciplinares, capturar o conhecimento dos processos, alinhá-los a uma estratégia, classificar se primários ou secundários afim de melhor compreender o que efetivamente contribui para melhor servir aos pacientes.

Um exemplo da má compreensão dos processos nos hospitais pode ser identificado no ato freqüente de se remover o prontuário do paciente da área assistencial para alimentar de informações os processos de faturamento. Entretanto, várias decisões médicas, de enfermagem e dos outros profissionais de saúde só são possíveis de serem adequadas com a disponibilidade dos dados e registros do paciente. Um novo antibiótico deve obrigatoriamente considerar os outros já utilizados e provavelmente uma escolha aleatória será inadequada. Alergias e intolerâncias serão desconhecidas sem a possibilidade de consulta aos registros prévios, possibilitando danos graves. O Serviço de Controle de Infecções utiliza os dados do prontuário para adequar os isolamentos de germes nocivos. Adicionalmente, uma análise dos resultados dos tratamentos realizados é fundamental para novas tomadas de decisões terapêuticas. Somente o desconhecimento da hierarquia dos processos e a falta de visão transdisciplinar podem explicar a priorização dos processos administrativos sobre os processos assistenciais, aumentando riscos de danos e lesões graves para o paciente, desviando o processo primário de seu desfecho efetivo. Indo a diante neste raciocínio, o faturamento perde seu sentido de faturar.

Como em qualquer negócio, os hospitais são organizados em torno de funções especializadas ou departamentos. Estes departamentos possuem seu próprio espaço físico, seus próprios orçamentos e empregados, e suas próprias estruturas gerenciais. Cada departamento tem seu próprio trabalho a executar, mas, fundamentalmente, tem um papel importante no pacote de valor entregue ao paciente. Os problemas maiores em hospitais são identificados nas interações - ou handoffs - entre estes departamentos ocasionados por uma falta de foco no paciente, ou cliente final.

De acordo com (Graban, 2009), os empregados dos hospitais tipicamente gastam um grande percentual do seu tempo com atividades desnecessárias. Por exemplo, enfermeiras em uma unidade de internação gastam de $25 \%$ a $50 \%$ do seu tempo efetivamente cuidando dos pacientes, incluindo: i) verificando o estado do paciente; ii) administrando medicação; iii) respondendo questões; e iv) dando suporte aos médicos.

Assim, para tratar pacientes mais efetivamente, hospitais precisam começar a visualizar o processo de ponta a ponta em detrimento de adotar apenas ações de melhoria pensando nos departamentos isoladamente. Executar melhorias nos departamentos individualmente traz um risco de subotimização da estrutura que pode até ajudar o departamento, mas coloca em risco todo o sistema.

Uma abordagem interessante para a avaliação de processos em hospitais é seguir o paciente, desde o início do processo até o final, procurando ver o processo com os olhos do paciente para que os pontos de melhoria possam ser identificados (foco DO cliente) (Shapiro, Rangan, \& Sviokla, 1992). A tabela $\mathrm{X}$ apresenta alguns possíveis pontos de início e fim para a análise do fluxo de pacientes em hospitais. 
Tabela 1: Possíveis pontos de início e fim para a análise do fluxo de pacientes em hospitais.

\begin{tabular}{|c|c|c|}
\hline Percurso do Paciente & Possíveis pontos de início & Possíveis pontos de encerramento \\
\hline \multirow{4}{*}{ Emergência } & Telefonema para uma ambulância & Saída da emergência (alta) \\
\hline & \multirow{3}{*}{ Chegada na porta do hospital } & Início de um procedimento laboratorial \\
\hline & & Mudança para o quarto \\
\hline & & Saída da internação (alta) \\
\hline \multirow{3}{*}{ Cirurgia ambulatória } & Chegada na porta do hospital & Início do procedimento \\
\hline & $\begin{array}{l}\text { Primeira ligação para } \\
\text { marcar um procedimento }\end{array}$ & Início do tratamento pós-anestésico \\
\hline & Primeiro atendimento pelo clínico geral & Alta \\
\hline \multirow{2}{*}{$\begin{array}{l}\text { Tratamento ambulatorial } \\
\text { de câncer }\end{array}$} & \multirow{2}{*}{ Chegada na porta do hospital } & Inicio do tratamento \\
\hline & & Alta \\
\hline \multirow{4}{*}{$\begin{array}{l}\text { Paciente de cirurgia } \\
\text { marcada }\end{array}$} & Chegada na porta do hospital & Início do procedimento \\
\hline & $\begin{array}{l}\text { Primeira ligação para } \\
\text { marcar o procedimento }\end{array}$ & Início do tratamento pós-anestésico \\
\hline & \multirow{2}{*}{ Primeiro atendimento pelo clínico geral } & Mudança para o quarto \\
\hline & & Alta \\
\hline \multirow{3}{*}{$\begin{array}{l}\text { Processo de alta de um } \\
\text { paciente }\end{array}$} & \multirow{3}{*}{ Médico escrevendo o pedido de alta } & Paciente pronto para deixar o hospital \\
\hline & & Paciente fisicamente fora do hospital \\
\hline & & $\begin{array}{l}\text { Quarto fisicamente pronto para o } \\
\text { próximo paciente }\end{array}$ \\
\hline \multirow{3}{*}{ Radiologia } & Pedido de um procedimento & Início do procedimento \\
\hline & Chegada no centro ambulatorial & Final do procedimento \\
\hline & Início do procedimento & Relatório verificado \\
\hline
\end{tabular}

Fonte: (Graban, 2009)

A escolha do ponto de início e fim para a observação de um processo dependerá, fundamentalmente, do tipo de problema que você estará tentando resolver, mas, fundamentalmente, deverá manter o foco no que é valor para o cliente final, ou seja, para o paciente do hospital.

\section{O QUE É VALOR?}

Conforme argumentam Womack e Jones (Womack \& Jones, 2003), valor somente pode ser definido pelo cliente final. A primeira pergunta então, no contexto dos hospitais, é "Quem é o cliente?". Em um ambiente hospitalar, podemos identificar diversos clientes para um determinado tipo de atividade ou cuidado que é proporcionado. O cliente final mais evidente é o paciente, no qual a maioria das atividades e prioridades deve direcionar seu foco de atuação.

Outros clientes podem incluir a família do paciente, médicos, empregados do hospital e quem aqueles que pagam as contas. Cada um dos diferentes clientes pode definir valor de uma maneira diferente. Por exemplo, um membro da família de um paciente que está sendo submetido à um procedimento cirúrgico pode encontrar valor no acompanhamento freqüente do estado de um paciente, reduzindo a preocupação e ansiedade.

A tabela 2, abaixo, sumariza alguns princípios importantes para a gestão de valor em ambientes hospitalares: 
Tabela 2: Princípios importantes para gestão de valor em ambientes hospitalares

\begin{tabular}{|c|c|}
\hline Princípio & Os hospitais precisam de: \\
\hline Valor & Especificar valor a partir do ponto de vista do cliente final, o paciente. \\
\hline Trajetória de Valor & $\begin{array}{l}\text { Identificar todos os passos que adicionam valor pelos diferentes } \\
\text { departamentos eliminando passos que não criam valor. }\end{array}$ \\
\hline Fluxo & $\begin{array}{l}\text { Manter os processos fluindo suavemente eliminando causas de atrasos } \\
\text { e problemas de qualidade }\end{array}$ \\
\hline Puxar & $\begin{array}{l}\text { Evitar empurrar o trabalho para o próximo processo ou departamento, } \\
\text { deixe o trabalho e os suprimentos serem puxados quando necessário. }\end{array}$ \\
\hline Perfeição & Buscar perfeição por meio da melhoria contínua de processos. \\
\hline
\end{tabular}

Fonte: Adaptado do Lean Enterprise Institute, "Principles of Lean", .http://www.lean.org/WhatsLean/Principles.cfm (accessado em 30 de agosto de 2010).

Apesar da necessidade de manter o foco no cliente final, é preciso também entender as necessidades dos clientes intermediários e na forma que o processo poderá auxiliar na trajetória de valor. Tomemos por exemplo, um médico que, trabalhando para o paciente, é o cliente direto de um relatório de um patologista. Quando uma biópsia de um paciente é enviada ao laboratório, o patologista tem que pensar acerca das necessidades do médico e nos critérios de qualidade, bem como nos do paciente. O médico que solicitou o exame pode ter requisitos específicos acerca de como a informação deverá ser apresentada e estruturada no relatório patológico. Em qualquer processo, a pessoa que executa o trabalho deverá pensar sobre o cliente final, mas também executar seu trabalho de uma forma que permita que o recebedor do trabalho, à jusante, seja um parceiro mais efetivo no esforço total de cuidar do paciente (Graban, 2009).

A fim de ilustrar o conceito de valor, (Graban, 2009) mapeou diferentes exemplos de atividades que geram valor e que não geram valor no ambiente hospitalar. As tabelas 3 e 4 sumarizam tais exemplos:

Tabela 3: Atividades que adicionam valor e que não adicionam valor por Função

\begin{tabular}{|c|c|c|c|}
\hline Setor & Função & $\begin{array}{l}\text { Exemplo de atividade } \\
\text { que adiciona valor }\end{array}$ & $\begin{array}{l}\text { Exemplo de atividade } \\
\text { que não adiciona valor }\end{array}$ \\
\hline $\begin{array}{l}\text { Centro } \\
\text { cirúrgico }\end{array}$ & Cirurgião & $\begin{array}{l}\text { Operar um paciente iniciando a } \\
\text { cirurgia no horário previsto }\end{array}$ & $\begin{array}{l}\text { Aguardando por paciente que demora } \\
\text { nos processos da internação }\end{array}$ \\
\hline Farmácia & $\begin{array}{c}\text { Técnico } \\
\text { farmacêutico }\end{array}$ & $\begin{array}{l}\text { Preparando uma solução } \\
\text { intravenosa }\end{array}$ & $\begin{array}{l}\text { Reprocessando medicamentos que } \\
\text { foram retornados das unidades de } \\
\text { tratamento }\end{array}$ \\
\hline $\begin{array}{l}\text { Unidade de } \\
\text { internação }\end{array}$ & Enfermeira & $\begin{array}{l}\text { Administrando medicamentos } \\
\text { nos pacientes }\end{array}$ & $\begin{array}{l}\text { Copiando e colando protocolos que } \\
\text { não serão utilizados como ferramentas }\end{array}$ \\
\hline Radiologia & $\begin{array}{l}\text { Técnico em } \\
\text { radiologia }\end{array}$ & $\begin{array}{l}\text { Executando um procedimento } \\
\text { de ressonância magnética }\end{array}$ & $\begin{array}{l}\text { Executando uma varredura médica } \\
\text { desnecessária }\end{array}$ \\
\hline & Patologista & $\begin{array}{l}\text { Interpretando um resultado de } \\
\text { um teste }\end{array}$ & $\begin{array}{l}\text { Consertando um instrumento com } \\
\text { defeito }\end{array}$ \\
\hline
\end{tabular}

Fonte: Adaptado de (Graban, 2009) 
Tabela 4: Atividades que adicionam valor e que não adicionam valor por produto

\begin{tabular}{|c|c|c|c|}
\hline Departamento & Produto & $\begin{array}{l}\text { Exemplo de atividade } \\
\text { que adiciona valor }\end{array}$ & $\begin{array}{l}\text { Exemplo de atividade } \\
\text { que não adiciona valor }\end{array}$ \\
\hline Emergência & $\begin{array}{l}\text { Diagnóstico } \\
\text { sindrômico dos } \\
\text { pacientes }\end{array}$ & $\begin{array}{l}\text { Triagem, exame clínico, } \\
\text { laboratorial e condutas de } \\
\text { urgência instituídas de pronto }\end{array}$ & $\begin{array}{l}\text { Esperar por atendimento ou } \\
\text { realização de procedimentos } \\
\text { que não são de emergência. }\end{array}$ \\
\hline $\begin{array}{l}\text { Laboratório } \\
\text { clínico }\end{array}$ & Laudo de exames & $\begin{array}{l}\text { Coleta adequada e } \\
\text { processamento das } \\
\text { amostras }\end{array}$ & $\begin{array}{l}\text { Coleta de exames em frascos } \\
\text { errados ou com técnica } \\
\text { inadequada }\end{array}$ \\
\hline Farmácia & $\begin{array}{l}\text { Medicamentos } \\
\text { aviados }\end{array}$ & $\begin{array}{l}\text { Medicação sendo formulada } \\
\text { ou preparada }\end{array}$ & $\begin{array}{l}\text { Medicação sendo inspecionada } \\
\text { diversas vezes }\end{array}$ \\
\hline $\begin{array}{l}\text { Central de } \\
\text { esterilização } \\
\text { de materiais }\end{array}$ & $\begin{array}{l}\text { Instrumentos } \\
\text { esterilizados }\end{array}$ & $\begin{array}{l}\text { Instrumentos sendo limpos e } \\
\text { esterilizados }\end{array}$ & $\begin{array}{l}\text { Esterilização de materiais não } \\
\text { críticos, ou reesterilização de } \\
\text { kits mal dimensionados. }\end{array}$ \\
\hline $\begin{array}{l}\text { Serviços } \\
\text { nutricionais }\end{array}$ & $\begin{array}{l}\text { Bandeja de } \\
\text { alimentos para o } \\
\text { paciente }\end{array}$ & $\begin{array}{l}\text { Alimento sendo preparado ou } \\
\text { bandeja sendo montada }\end{array}$ & $\begin{array}{l}\text { Retrabalho, pois a bandeja foi } \\
\text { montada de forma inadequada }\end{array}$ \\
\hline
\end{tabular}

Fonte: Adaptado de (Graban, 2009)

A identificação de quando uma atividade adiciona ou não valor ao cliente não é sempre uma tarefa fácil e óbvia. O ambiente organizacional, sobretudo o hospitalar, é dotado de uma rede complexa de processos que precisam ser entendidos de forma ampla e sistêmica com o foco no cliente final, o paciente. Um exemplo é um processo que atualmente recebe investimento relevante nas instituições que consiste no "diagnóstico da enfermagem". Se o produto final é cliente tratado (mas nem sempre satisfeito), numa gestão de processo apenas o diagnóstico do paciente é relevante. O diagnóstico deve ser construído pelas várias profissões, mas são todos do paciente para construção do Projeto Terapêutico e não da enfermagem, dos médicos ou dos fisioterapeutas. O simples fato de um paciente de um hospital possuir diversos prontuários e diagnósticos, um prontuário e um diagnóstico para cada profissão - médico, fisioterapeuta, psicólogo, etc. -, é um forte indício de um foco de uma gestão por funções em detrimento de uma orientação para processos o que dificulta, indubitavelmente, a percepção dos stakeholders do processo acerca do que efetivamente adiciona valor para o cliente final. Por outro lado, de acordo com (Graban, 2009), é preciso compreender que o ato de identificar as atividades que não adicionam valor e geram perdas pode ser arriscado.

Frequentemente quando identificamos as atividades que não adicionam valor e geram perdas as levam para o lado pessoal, especialmente se elas criaram o sistema atual ou tem trabalhado por muito tempo nele. É preciso compreender que ao descrever as atividades que não adicionam valor ao processo "Este processo parece ter várias atividades que não adicionam valor" é diferente de fazê-lo com foco nas pessoas "Você está gastando muito recurso para fazer seu trabalho". Quando personalizamos o problema, intencionalmente ou não, as pessoas assumirão uma postura defensiva e frequentemente procuram racionalizar o processo atual. As pessoas normalmente têm orgulho da forma que elas fazem seu trabalho, mesmo quando ele está repleto de atividades que não adicionam valor.

Uma enfermeira que sabe para onde correr para encontrar um cobertor quando eles parecem ter acabado pode ser percebida como uma heroína por ter direcionado um esforço extra para executar seu trabalho. Quando adotamos uma visão para o que é realmente valor, deveríamos nos perguntar o motivo pelo qual a mesma enfermeira está correndo desesperadamente todos os dias pelo mesmo motivo e procurar melhorar o sistema para que os cobertores fiquem disponíveis no lugar certo e nas quantidades corretas a fim de evitar esforços heróicos.

Pensando neste exemplo, podemos afirmar que o processo que gera maior valor é aquele que está mais alinhado à estratégia, e agregar valor aos clientes internos só será relevante se também agregar valor ao cliente final. Alguns valores serão agregados apenas para os clientes internos e nem percebidos pelo cliente final, mas nada poderá ser agregado se prejudicar a efetividade dos tratamentos. 


\section{CONSIDERAÇÕES FINAIS}

Provavelmente, a definição mais concisa para "processos de negócio" foi aquela sugerida por Michael Hammer (Hammer, 2001) considerando o conceito como um grupo organizado de atividades relacionadas que, juntas, criam um resultado de valor para os clientes. Importante ressaltar que atividades distintas, executadas por uma única ou por múltiplas funções ou empresas, reúnem-se para entregar resultados, gerando o pacote de valor para um cliente. As operações, sobretudo no setor de saúde, precisam se certificar que o foco é mantido em tudo aquilo que brilha os olhos dos clientes e satisfaçam suas necessidades. Torna-se, portanto, necessário alinhar os processos-chave da organização e suas inter-relações, nas suas diversas perspectivas e especialidades, com os recursos físicos, humanos, estoques, informação e conhecimento.

No segmento da saúde, especialmente, o aumento da complexidade dos processos alinhado à escassez cada vez maior de recursos, de diversas naturezas, tem exigido das organizações uma maior profissionalização na gestão e, consequentemente, níveis de serviço superiores a um menor custo. Paralelamente, a busca das organizações pelo foco nas competências essenciais (core competencies) tem impulsionado um movimento de terceirização de algumas atividades que, inevitavelmente, gera maior complexidade na gestão dos processos e uma maior pulverização da informação entre os atores. Diante de tal cenário e da discussão conduzida por este ensaio, sugere-se que os processos no setor de saúde urgem por uma gestão mais transdisciplinar, em que o papel dos diversos atores, e suas diferentes visões da organização, possam ser compatibilizados com a expectativa de valor do cliente final, em primeiro lugar. Há, portanto, uma necessidade cada vez maior das organizações que atuam no segmento da saúde de, para se manterem competitivas e alinhadas às necessidades de seus clientes, de adotar uma gestão transdisciplinar de seus processos considerando o conjunto diversificado de maneira sinérgica de todas as disciplinas, especialidades, setores e profissionais.

\section{REFERÊNCIAS}

Estadão. (27 de Agosto de 2010). Cinco hospitais se unem por turismo médico. Acesso em 30 de Agosto de 2010, disponível em Estadão: http://www.estadao.com.br/estadaodehoje/20100827/not_ imp601079,0.php

Graban, M. Lean hospitals : improving quality, patient safety, and employee satisfaction. NY: Taylor \& Francis Group, 2009.

Grossman, M. On the concept of health capital and the demand for health. Journal of Political Economy , v. 80, n.2, 223-255, 1972.

Hammer, M. The Agenda: What Every Business Must Do to Dominate the Decade. Crown Business Publishing Gr, 2001.

IBGE. Estatísticas da saúde : assistência médico-sanitária 2005, 2006.

Infante, M., \& Santos, M. A. A organização do abastecimento do hospital público a partir da cadeia produtiva: uma abordagem logística para a área de saúde. Ciência e Saúde Coletiva , v.12, n.4, 945-954, 2007.

Lee, H. L., \& Billington, C. Managing supply chain inventory: pitfalls and opportunities. Sloan Management Review , v.33, n.3, 1992.

Morin, E. Introdução ao pensamento complexo. Porto Alegre: Sulina, 2005

Murray, A. The Wall Street Journal Essential Guide to Management. NY: Harper Business, 2010.

Normann, R., \& Ramírez, R. From Value Chain to Value Constellation: Designing Interactive Strategy. Harvard Business Review, v.71, n.4, 1993.

SCHNEIDER, A. P. FORNECIMENTO DE HORTIFRUTIGRANJEIROS PARA UNIDADES DE ALIMENTAÇÃO E NUTRIÇÃO HOSPITALARES. Ciência e Tecnologia de Alimentos ,v. 26, n. 2, pp. 253-258, 2006.

Shapiro, B. P., Rangan, V. K., \& Sviokla, J. J. Staple yourself to an order. Harvard Business Review, pp. 113-121, 1992.

Womack, J. P., \& Jones, D. T. Lean Thinking: Banish Waste and Create Wealth in Your Corporation. London: Simon \& Schuster, 2003.

Yaxiong, T., Zhen, X., Guoquan, Z., \& Boqing, L. A Research on BPM System based on Process Knowledge. Cybernetics and Intelligent Systems (pp. 69-76). IEEE Conference on, 2008. 